\title{
El Corpus PUCV-2006 del Español: identificación y definición de los géneros discursivos académicos y profesionales*
}

\author{
Giovanni Parodi ${ }^{* *}$, Romualdo Ibáñez ${ }^{* * *}$, René Venegas ${ }^{* * *}$
}

\section{Resumen}

En este artículo, se identifican, definen y clasifican los géneros discursivos emergentes de los 933 textos que componen el Corpus del Español Académico y Profesional PUCV-2006. Con el fin de lograr estos objetivos, se lleva a cabo una metodología complementaria de tipo deductiva-inductiva. Para la identificación de los géneros se han utilizado cinco criterios: Macropropósito Comunicativo, Relación entre los Participantes, Modo de Organización del Discurso, Modalidad y Contexto Ideal de Circulación. Luego del análisis de todos los textos, se identificaron y se agruparon 29 géneros, posteriormente se definieron y clasificaron estos géneros según los cinco criterios y veintiséis variables asociadas a ellos. Entre los resultados más relevantes se destaca que los géneros académicos y profesionales escritos, en su mayoría, responden al macropropósito de consignar información, se organizan predominantemente a partir de un modo discursivo de tipo descriptivo y se establece, predominantemente, una relación entre escritores y lectores expertos.

Palabras clave: Género, Discurso, Macropropósito comunicativo, Corpus del Español Académico y Profesional.

\section{Abstract}

In this article, we identified, defined, classified, and exemplified the discourse genres that have emerged from the 933 texts forming the PUCV-2006 Academic and Professional Corpus of Spanish. To accomplish these objectives, we adopt a deductive-inductive complementary methodology. Five criteria were selected and employed in order to classify the texts: Communicative Macro-purpose, Relation between the Participants, Mode of Discourse Organization, Modality, and Ideal Context of Circulation. Based on the corpus analysis, we identify twenty-eight genres according to the criteria mentioned above. Among our findings, we can say that most identified genres share consigning information, as their communicative purpose. Also, that they are predominantly organized in a descriptive mode. And, that the relation between participants is established between experts.

Key words: Genre, Discourse, Communicative macro-purpose, Academic and Professional Corpus of Spanish.

* Investigación financiada por el proyecto FONDECYT № 1060440.

* Dr. en Lingüística, académico Pontificia Universidad Católica de Valparaíso. gparodi@ucv.cl

*** Dr. en Lingüística, académico Pontificia Universidad Católica de Valparaíso. romualdo.ibanez@ucv.cl

**** Dr. en Lingüística, académico Pontificia Universidad Católica de Valparaíso. rene.venegas@ucv.cl 
El Corpus PUCV-2006 del Español: identificación y definición de los géneros discursivos académicos y profesionales / Giovanni Parodi, Romualdo Ibáñez y René Venegas

\section{Introducción}

En este artículo buscamos identificar, clasificar y definir y los géneros discursivos que emergen a partir de un corpus de 933 textos escritos, recolectados en cuatro ámbitos disciplinares universitarios y en sus respectivos entornos profesionales. De este modo, el foco de esta investigación está circunscrito al estudio de rutinas convencionalizadas que constituyen lo que en nuestra perspectiva son géneros del discurso (Parodi, 2009a). Para ello, diseñamos un marco de análisis que emerge de un conjunto de criterios de diversa naturaleza, los que se operacionalizan en un grupo más específico de variables. Para llegar a la identificación y definición de cada género, recurriremos a una metodología de corte inductivo-deductiva, a través de la cual complementamos categorías pre-existentes en la mente de los investigadores junto a información proveniente del análisis de los datos mismos. Desde un enfoque multidimenciones y multiplanos, defendemos la interacción entre fases cognitivas, sociales, comunicativo-funcionales y lingüísticas. Buscamos llegar a una determinación y clasificación de los géneros con el mayor grado de profundidad posible y así poder identificar rasgos distintivos y diferenciadores entre unos y otros géneros.

Como es bien sabido, la identificación y clasificación de tipos, clases y/o géneros del discurso ha sido un interés permanente a lo largo del desarrollo de los estudios lingüísticos. En particular, desde que se ha tomado conciencia de la naturaleza compleja de objetos tales como los géneros discursivos, se han llevado a cabo esfuerzos diversos por intentar distinguirlos y agruparlos a partir de ciertos rasgos o características más prototípicas. Todo ello ha ido cobrando progresivamente mayor fuerza en los últimos años. Hoy en día, tanto la perspectiva de análisis como las variables a considerar para llevar a cabo una identificación y clasificación son materia de interesantes discusiones. Básicamente, se distinguen dos enfoques de análisis: uno deductivista (guiado por la teoría o descendente) -basado en criterios a priori, los cuales pueden provenir de una o varias 
teorías-y otro empirista (guiado por los datos o ascendente). También es factible, como en el caso de nuestro estudio, aplicar un enfoque combinatorio en que se parte de categorías predefinidas y se complementan estos rasgos preliminares con otros emergentes a partir del estudio de los datos en análisis. Sea que se opte por uno u otro enfoque, también es necesario decidir respecto a si habrá una sola variable involucrada o si será un enfoque multirasgos y multidimensiones.

Ahora bien, desde este escenario descrito, en la primera parte de este artículo, nos focalizamos en una breve revisión de conceptos, criterios y variables fundamentales para enmarcar el presente estudio. A ello lo sigue el apartado en que damos cuenta de la investigación, en el cual se presenta una breve descripción del corpus de textos en estudio y se entregan detalles acerca de los procedimientos metodológicos. Como parte de los resultados, mostramos la emergente identificación de géneros académicos y profesionales y las definiciones a las que hemos arribado desde nuestra matriz de criterios y variables. Hacia la parte final del trabajo, se realiza un primer análisis de los géneros identificados a partir de los criterios y de las variables involucradas. Se cierra el artículo con algunos comentarios y proyecciones.

Por último, cabe destacar que, como un modo de hacer más transparente la determinación de cada género y su definición, pero atendiendo a las limitaciones de espacio en este artículo, se ha procedido a seleccionar y levantar en un sitio en Internet, un pasaje representativo de un texto del corpus, a modo de ejemplo de cada género en cuestión.

\section{Precisiones teóricas}

En principio es relevante dejar en claro que en este artículo no abordamos la discusión del concepto de género ni entramos en su definición, pues suscribimos los principios propuestos y desarrollados por Parodi (2009a). Por ello, el foco de este estudio está en la discusión respecto de un marco de análisis de criterios y variables que permitan identificar, clasificar y alcanzar definiciones operacionales. Baste señalar que la concepción a la que adherimos es una compleja y dinámica en que los géneros son entendimos como constructos multidimencionales en que al menos es posible identificar tres dimensiones: cognitiva, social y lingüística. Desde este enfoque teórico, la búsqueda de una matriz de criterios y variables enfrenta una tarea desafiante, la que iniciamos en este trabajo.

Clásicamente, las tipologías textuales o de géneros discursivos han tendido a configurarse en torno a distinciones categoriales, a partir de criterios discretos, para así clasificar los objetos en estudio. Desde la lin- 
El Corpus PUCV-2006 del Español: identificación y definición de los géneros discursivos académicos y profesionales / Giovanni Parodi, Romualdo Ibáñez y René Venegas

güística del texto en sus inicios, este fue uno de los objetivos primordiales. Desde la Lingüística Sistémica Funcional (LSF) y la teoría de los géneros, Martin y Matthiessen $(1991)$ y Martin $(1993,1996,2002)$ han mostrado la utilidad del concepto de topología (en oposición a tipología) para la identificación de géneros y sus agrupaciones. Del concepto de topología se desprende el de gradación dentro de un espacio semiótico, más que una concepción basada en un conjunto finito de categorías discretas.

Esta búsqueda por una mayor sofisticación, atendiendo a una categorización más rigurosa, proviene de vertientes diversas tales como adaptaciones de la clásica teoría de Wittgenstein (1958) en que se distingue "semejanzas de familias", de la propuesta de Rosch (1975) a partir de la teoría de los prototipos, o del concepto de categorías de límites difusos (fuzzy categories), acuñado por Lakoff (1972) desde la Lingüística Cognitiva. En este sentido, el concepto de topología y de gradación desde la LSF se aproxima al de categorías de límites difusos de la Lingüística Cognitiva, aunque claramente desde opciones epistemológicas diversas. Estas ideas de límites porosos también son compartidas por los estudios en lingüística textual en cuanto a taxonomías complejas de tipo multidimensionales o multiniveles (Bassol \& Torrens, 1997; Ciapuscio, 2003; Parodi y Gramajo, 2003). Como se puede apreciar, los avances en diversas líneas han ampliado y profundizado nuestra comprensión del fenómeno complejo que involucra a los procesos de categorizar y clasificar.

Ahora bien, tanto la tipología textual clásica, la topología, las categorías de límites difusos como los enfoques multidimensionales y multiniveles comparten ciertos supuestos que no se encuentran en oposición. Lo que rescatamos de todas estas aproximaciones es el objetivo común por clasificar, pero con la conciencia, por una parte, de que los objetos tienen límites porosos y, por otra, de que se puede aplicar diversas dimensiones o criterios variados desde diversos planos para el análisis. Estamos ciertos que estas aproximaciones complejas en que coexisten aspectos, por ejemplo, de tipo cognitivo, lingüístico y funcional/comunicativo pueden brindar descripciones y explicaciones mucho más profundas de los fenómenos en estudio. Justamente adoptamos esta perspectiva multidimensional, pues ella es coherente con nuestro concepto de género del discurso, tal como se expone en Parodi (2009a). Dado que concebimos a los géneros discursivos como unidades altamente complejas y dinámicas, en cuya conformación la dimensión cognitiva, la dimensión social y la dimensión lingüística se proponen como esenciales, un enfoque de varias dimensiones es el adecuado para la elaboración de clasificaciones válidas desde un punto de vista tanto teórico como empírico. Así, la dimensión lingüística ejerce un rol fundamental y sinérgico entre las tres, pero a la vez establece un nexo entre las otras dos. Para que mucho de lo que acontece en el mundo social alcance un estatus cognitivo, el 
lenguaje verbal -como herramienta central de la vida humana- vehicula la semiosis hacia un sustrato cognitivo y, a la vez, reconstruye el mismo hecho semiótico complejo (Parodi, 2008).

En este estudio buscamos identificar los géneros académicos y profesionales del Corpus PUCV-2006 y proponer una definición operacional de cada uno de ellos, partimos del supuesto de que, por una parte, existen criterios definitorios apriorísticos que pueden operar en conjunto con otros emergentes a partir de los datos. Es, entonces, el conjunto de criterios y variables que se conjugan en forma simultánea el que permite establecer distinciones entre un género y otros. Desde esta perspectiva, es evidente que algunos géneros se acercarán a otros y sus fronteras serán más difusas que con otros. También queda claro que, en algunos casos, uno o dos criterios se constituirán en los diferenciadores por excelencia, mientras en otros serán justamente el punto de encuentro y porosidad difusa.

En este afán descriptivo y clasificatorio nos apoyamos complementariamente en métodos deductivistas y otros más inductivistas. Esto quiere decir que no nos preocupa complementar categorías teóricas emergentes desde el conocimiento previo de los investigadores con datos empíricos provenientes de una mirada más "basada-en-el-corpus" (Tognini-Bonelli, 2001; Biber, Connor \& Upton, 2007). De modo que la complementariedad de enfoques es un asunto central para alcanzar, en nuestro caso, una mejor y más acotada distinción entre los géneros del corpus. Así, para llevar adelante la clasificación, se consideró en un principio tanto las características internas de los textos como el contexto extralingüístico en el cual estos se producen y circulan. Dicho enfoque tiene sus fundamentos en el carácter eminentemente dialógico del lenguaje e intenta dar cuenta de la compleja relación lingüístico-cognitivo-social entre los participantes de una determinada comunidad discursiva.

\section{La investigación}

\subsection{El corpus}

En lo que sigue presentamos una breve descripción cuantitativa del corpus en estudio. Vale la pena mencionar que existe una importante diferencia entre los procedimientos de recolección del Corpus Académico y del Corpus Profesional. En lo que respecta al académico, se buscaba recolectar cerca del $100 \%$ del material escrito que se consulta y se lee durante el total de años del currículo de cada una de las cuatro carreras universitarias: Psicología (PSI), Trabajo Social (TS), Ingeniería en Construcción (IC) y Química Industrial (QUI). Paralelamente, también se recogieron 
los textos que circulan y a los que se exponen los profesionales egresados de estas carreras y que se desempeñan en ámbitos propios a los de su formación de origen. Cabe señalar que para el Corpus Profesional no se persiguió la recolección exhaustiva de todos los textos en circulación. Ello pues es claro que en este ámbito este material es ilimitado. Lo que nos interesaba era construir un panorama de la diversidad de géneros que circulaban como medios de comunicación escrita en estos cuatro ámbitos laborales. La siguiente tabla resume la información de ambos corpus.

Tabla 1. Dimensionamiento del Corpus Académico y Profesional

\begin{tabular}{|l|l|c|c|c|}
\hline \multirow{2}{*}{$\begin{array}{l}\text { Ámbito de la } \\
\text { Ciencia }\end{array}$} & Disciplina & \multicolumn{3}{|c|}{ Número de Textos } \\
\cline { 2 - 5 } & & Corpus Académico & Corpus Profesional & Totales \\
\hline $\begin{array}{l}\text { Ciencias Sociales y } \\
\text { Humanas (CS \& H) }\end{array}$ & Psicología & 227 & 220 & 447 \\
\cline { 2 - 5 } & Trabajo Social & 142 & 101 & 243 \\
\hline $\begin{array}{l}\text { Ciencias Básicas } \\
\text { y de la Ingeniería } \\
\text { (CB \& I) }\end{array}$ & $\begin{array}{l}\text { Ingeniería en } \\
\text { Construcción }\end{array}$ & 69 & 62 & 131 \\
\cline { 2 - 5 } & Química Industrial & 53 & 59 & 112 \\
\hline & Totales & 491 & 442 & 933 \\
\hline
\end{tabular}

Una primera mirada a los datos de esta tabla revela que existe un mayor número de textos recolectados en las disciplinas de las Ciencias Sociales y Humanas (SC\&H), a diferencia de lo que ocurre en las disciplinas de las Ciencias Básicas y de la Ingeniería (CB\&l). Ello indicaría que los alumnos de CS\&H leerían una mayor cantidad de textos que los alumnos de las CB\&I. Según estas cifras, se aprecia, por ejemplo, que los alumnos de Psicología leerían cuatro veces más que los alumnos de Química Industrial tanto en número de textos como de palabras. La misma situación se detecta en cuanto al corpus profesional y en las mismas disciplinas. Todo ello revela una cierta tendencia a asociar un área del conocimiento y sus disciplinas, tanto en el ámbito académico como en lo profesional, con una mayor cantidad de textos y textos más extensos, como ocurre con PSI y TS. Mayores detalles analíticos del corpus se encuentran en Parodi (2008).

\subsection{Marco de análisis: Criterios y variables para identificar géneros discursivos}

La Figura 1 captura algunos de los rasgos constitutivos de los géneros discursivos en que basaremos nuestro análisis. A partir de la conjugación de criterios y su operacionalización en variables más específicas es posible hacer emerger un género particular. Cuando algunos de los componentes nucleares que constituyen un determinado género evolucionan y comienzan a realizarse en otras variables específicas, resulta factible que otro género emerja. 
Figura 1. Componentes de los géneros discursivos

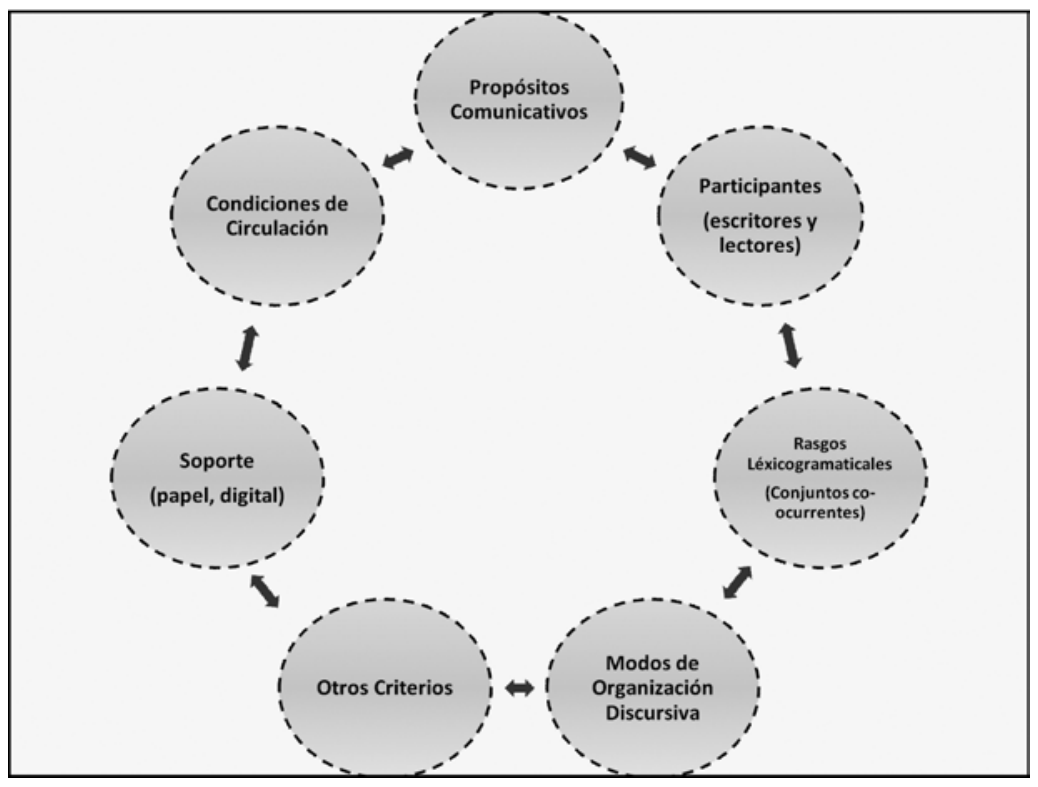

Como se aprecia, en la Figura 1, la constitución del género queda abierta a nuevos componentes nucleares o satelitales, puesto que los criterios y variables operacionalizables no están determinados definitivamente y es posible incluir variables que permitan una identificación más afinada. Queda claro que estos seis criterios se proponen a modo de categorías iniciales de indagación, pero no como definitivas.

Tal como se indicó, la construcción de esta propuesta de identificación y clasificación obedeció a principios de un enfoque deductivo/inductivo. El paso deductivo nos llevó a "partir de los tipos ya definidos e instituidos tradicionalmente como objetos lingüísticos observables" (De Beaugrande \&Dressler, 1981:251) para, sobre esa base, identificar y seleccionar criterios y variables basados en la bibliografía especializada. Posteriormente, con el objetivo de complementar y afinar esta primera matriz de rasgos, se procedió a indagarla empíricamente en un microcorpus. A través de estos procedimientos, se llegó a una matriz definitiva que permitió distinguir y clasificar con mayor precisión los textos del corpus. El conjunto de estos criterios y variables abarca, entre otros, aspectos que dicen relación con los propósitos comunicativos, la interacción entre escritores y lectores, los contextos en que los textos circulan y los modos predominantes de organizaciones discursivas que caracterizan los textos del corpus.

De modo más preciso, para el presente estudio, hemos diseñado un marco de análisis en que focalizamos cinco criterios fundamentales. 
Como se observa en la Figura 2, estos criterios son: a) macropropósito comunicativo, b) modo de organización del discurso, c) relación entre los participantes, d) contexto ideal de circulación y e) modalidad.

Figura 2. Selección de criterios para una identificación de géneros

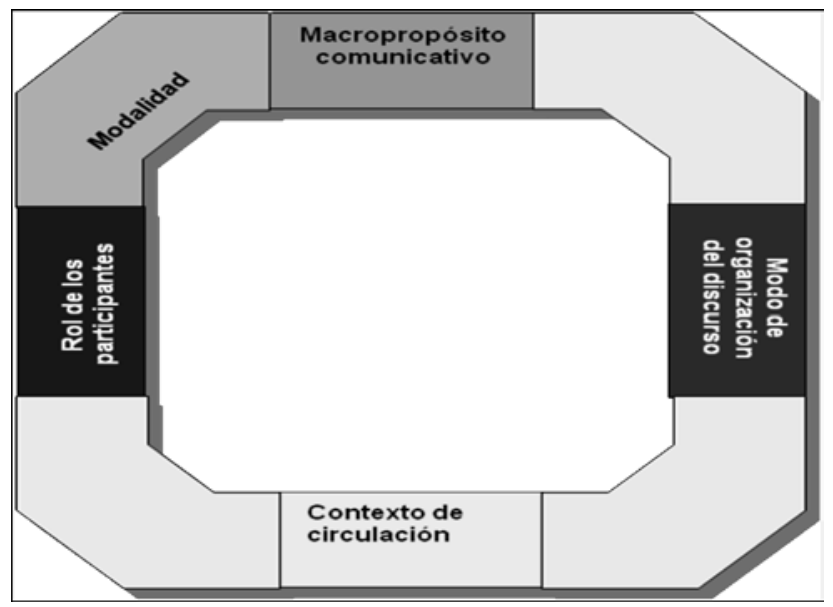

Como se indicó, de estos cinco criterios iniciales emerge un conjunto de veintiséis variables más específicas. Estas variables se analizan en los textos bajo el principio de "predominancia" de una sobre otra. Esto quiere decir que estamos conscientes de que, tal como se ha venido enfatizando más arriba, los textos y los géneros no son unidades absolutamente circunscritas ni cerradas en sí mismas. En ellos, por ejemplo, coexisten diversos macropropósitos comunicativos y a lo largo de sus pasajes se intercalan múltiples modos de organización discursiva. Del mismo modo, en esta figura, se aprecia que la matriz de criterios queda abierta a nuevas posibilidades en los espacios en blanco en las esquinas disponibles.

La Figura 3 presenta las variables establecidas para cada criterio. 
Figura 3. Criterios y variables clasificatorias del género

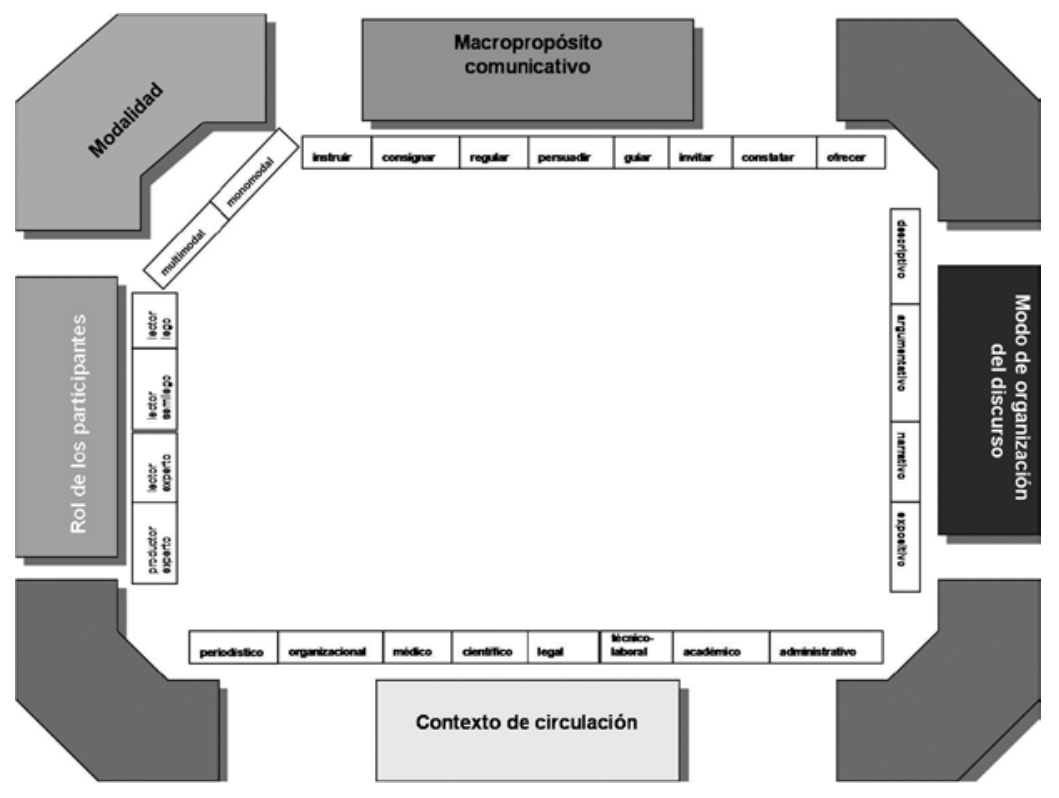

Vale la pena insistir en que el diseño presentado en las figuras anteriores busca rescatar la idea de apertura hacia nuevos criterios y variables. Esto quiere decir que enfatizamos un marco de análisis inicial el que en posteriores investigaciones y a partir de esta utilización se enriquezca progresivamente.

A continuación se definen cada uno de los criterios y sus variables:

3.2.1 Macropropósito Comunicativo: Antes de presentar lo que en esta investigación entendemos por macropropósito comunicativo, es preciso enfatizar la idea de que los textos, como instancias concretas de una lengua particular, son producidos por los individuos en forma intencionada, de acuerdo a las necesidades que el contexto les impone. Por esta razón, cada evento comunicativo o texto posee un propósito que lo origina y que, al mismo tiempo, junto a otras variables, permite identificarlo como un ejemplar de un género discursivo determinado (Askehave \& Swales, 2001). Este propósito es denominado por algunos autores como Propósito Comunicativo del género (Swales, 1990, 2001, 2004; Bhatia, 1993, 1997, 2004; Dudley-Evans, 1994).

El Propósito Comunicativo es concebido como el objetivo último para el cual un género discursivo es utilizado en un intercambio comunicativo. En tanto gran parte de los géneros que componen nuestro corpus se caracteriza por poseer no solo un propósito comunicativo general, sino que 
también un conjunto de propósitos comunicativos menores, a partir de los cuales el propósito general se configura, identificamos tal propósito general como Macropropósito Comunicativo (ver Parodi, 2009b). Los macropropósitos identificados en este estudio son:

- Instruir acerca de una materia disciplinar específica

- Consignar información respecto del estado de un procedimiento, de la salud de un individuo o de un concepto.

- Regular conductas y/o procedimientos.

- Persuadir acerca de un planteamiento teórico o ideológico.

- Guiar conductas y/o procedimientos.

- Invitar a participar de un concurso público.

- Constatar la validez de un hecho o procedimiento.

- Ofrecer un producto o servicio.

3.2.2 Relación entre los participantes: Para describir la relación entre los participantes es preciso aproximarse al concepto de comunidad discursiva. Este tipo de comunidad se constituye por un grupo de personas que comparten un conjunto de conocimientos, así como también las convenciones necesarias para interactuar discursivamente y compartir tales conocimientos. De acuerdo a Swales $(1990)$ y Bhatia $(1993,2004)$, las comunidades discursivas existen y se sustentan por medio de una membresía dinámica en términos de experticia. Esto se debe a que los miembros que las componen, en la mayoría de los casos, ingresan a la comunidad como aprendices y se transforman paulatinamente en expertos, a partir de su interacción discursiva en dicha comunidad. De este modo, los roles del habla (Halliday \& Hasan, 1976; Halliday, 2004) que las personas pueden adoptar en un intercambio comunicativo como hablante/ escritor y oyente/lector, se proyectan en una comunidad discursiva como roles determinados por el grado de experticia de los participantes.

Aun cuando reconocemos que la estabilidad de una comunidad discursiva se basa en un desarrollo continuo de la experticia de sus miembros, por razones metodológicas, hemos establecido cuatro roles centrales: escritor experto, lector experto, lector semilego, lector lego. Tanto el escritor como el lector experto corresponden a miembros con un alto grado de experticia, lo que les permite no solo comprender los géneros que circulan en su comunidad, sino que también producirlos. El lector semilego posee una experticia intermedia, por lo que si bien ha adquirido ciertos conocimientos compartidos por la comunidad, aún no es capaz de interactuar eficazmente a través de la totalidad de los géneros que circulan en dicha comunidad. Por último, el lector lego corresponde al miembro con menor grado de experticia. Basados en los roles anteriormente señalados, hemos identificado tres relaciones 
prototípicas entre los participantes, las cuales entendemos desde una perspectiva ideal. Estas relaciones se muestran en la Figura 4.

Figura 4. Relaciones entre los participantes

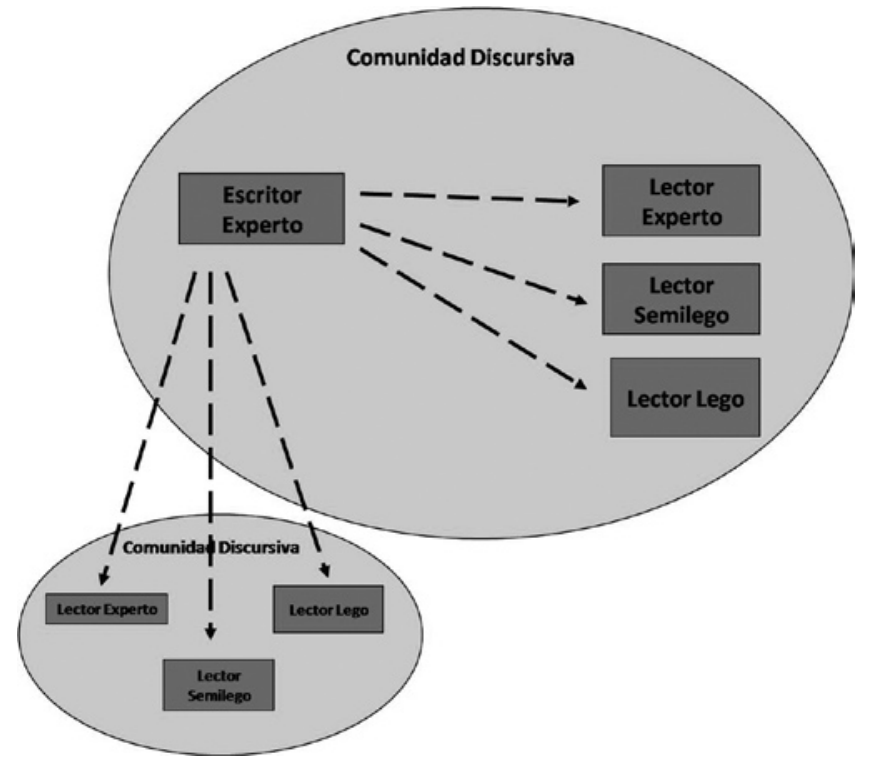

Como se aprecia en la Figura 4, las relaciones discursivas prototípicas corresponden a las existentes entre un escritor experto y un lector experto, entre un escritor experto y un lector semilego y entre un escritor experto y un lector lego. No obstante ello, es relevante señalar que, si bien los géneros discursivos son concebidos por algunos autores como elementos identitarios de las comunidades discursivas (Swales, 1990, 2001; Bhatia, 1993, 2004), en muchos casos, su circulación no se limita a una única comunidad. Por lo mismo, no podemos dejar de reconocer la posibilidad de una relación entre un escritor experto de una comunidad discursiva (1) con un lector miembro de otra comunidad (2), como se puede observar en la Figura 4. Esto asegura que un texto, producido dentro de una determinada comunidad, pueda ser objeto de lectura como parte del discurso de otra comunidad, muy posiblemente sirviendo otros propósitos comunicativos.

3.2.3 Modo de organización del discurso: Los modos de organización del discurso son tipos básicos de enunciados que expresan diferentes formas de organizar el discurso, los cuales permiten la secuenciación de los contenidos y definen al género como predominantemente descriptivo, narrativo o argumentativo. Desde una perspectiva más concreta, es posible establecer que los modos de organización del discurso responden a tipos relativamente estables de combinación de enunciados, a través de los cuales se identifica una organización reconocible por su 
estructura jerárquica interna y por su unidad compositiva (Charaudeau, 1992; Adam, 1992; Parodi y Gramajo, 2003). A continuación se describen estos tres modos.

- Modo Descriptivo: Este modo de organización del discurso presenta tres tipos de componentes: nombrar, localizar- situar y calificar. Estos permiten caracterizar objetos, personas, situaciones o procesos, a partir de sus cualidades o circunstancias temporales y espaciales. A través de este modo se puede organizar la información como listas de ítemes, como ordenamientos taxonómicos, como definiciones de un tipo o un arquetipo de acción, procedimiento o personaje (Hamon, 1991; Charaudeau, 1992; Adam, 1992).

- Modo Narrativo: Este modo de organización del discurso dispone las acciones y los acontecimientos en un orden temporal integrador, dando unidad y orientando la acción hacia un fin; de manera tal que si una de las partes de la acción es desplazada o suprimida, el todo se altera. Este modo de organización se caracteriza por la presencia de una alta densidad de relaciones causa-efecto, de propósito, de posibilidad y de proximidad temporal (Propp, 1928; van Dijk, 1983; Charaudeau, 1992; Adam, 1992).

- Modo Argumentativo: Este modo de organización del discurso dispone la información en un orden lógico, demostrativo o persuasivo. El centro de la argumentación lo constituye la tesis, núcleo fundamental en torno al cual se reflexiona y se elaboran argumentos para sostenerla o refutarla (Lo Cascio, 1998; Toulmin, 1958; van Dijk, 1983; Charaudeau, 1992; Adam, 1992).

3.2.4 Contexto de circulación ideal: Este criterio da cuenta del contexto en que, idealmente, los textos correspondientes a un género son empleados. Distinguiéndose contextos más especializados y de circulación restringida y otros más amplios, generales y con un menor grado de restricción. Algunos contextos de circulación identificados en este estudio son:

- Pedagógico: ámbito formal de enseñanza y aprendizaje de contenidos y procedimientos.

- Laboral: ámbito en el que se ejecuta una actividad técnica o profesional.

- Científico: ámbito en el que se generan y transmiten conocimientos producto del quehacer investigativo.

- Universal: ámbito que involucra a todos los anteriores, pero que, al mismo tiempo, incluye contextos de circulación amplia que implican a la sociedad como un todo. Ello quiere decir que no se restringe a contextos de circulación reducida ni altamente especializados. 
3.2.5 Modalidad: La modalidad corresponde al modo (o modos) semiótico(s) utilizado(s) en los géneros discursivos para construir la red conceptual del mensaje y darle sentido al mismo. Estos modos se materializan a partir de dos tipos de signos: verbales (orales o escritos) y no verbales (fórmulas científicas, imágenes, dibujos, ilustraciones, etc.) (Pierce, 1965; Eco, 2000; Kress \& van Leeuwen, 2001). Para este estudio, este criterio se operacionaliza de forma dicotómica, con predominancia de uno u otro modo. Ellos son:

- Monomodal: es decir, se presenta predominantemente en el género un modo semiótico, verbal (oral o escrito) o no verbal (gráficos, señales, tablas, esquemas, imágenes, etc).

- Multimodal: es decir, se presenta predominantemente en el género más de un modo semiótico, verbal (oral o escrito) y no verbal (gráficos, señales, tablas, esquemas, imágenes, etc).

\subsection{Ejemplo de clasificación de géneros a partir de la matriz de criterios y variables}

Como una forma de mostrar el modo de empleo de los criterios y variables seleccionados en la identificación y comparación de géneros, en la Figura 5, se presenta una caracterización de los géneros Texto Disciplinar y Manual. Estos dos géneros han sido identificados mediante la aplicación de la matriz de rasgos.

Figura 5. Ejemplo de identificación de los géneros Texto Disciplinar y Manual

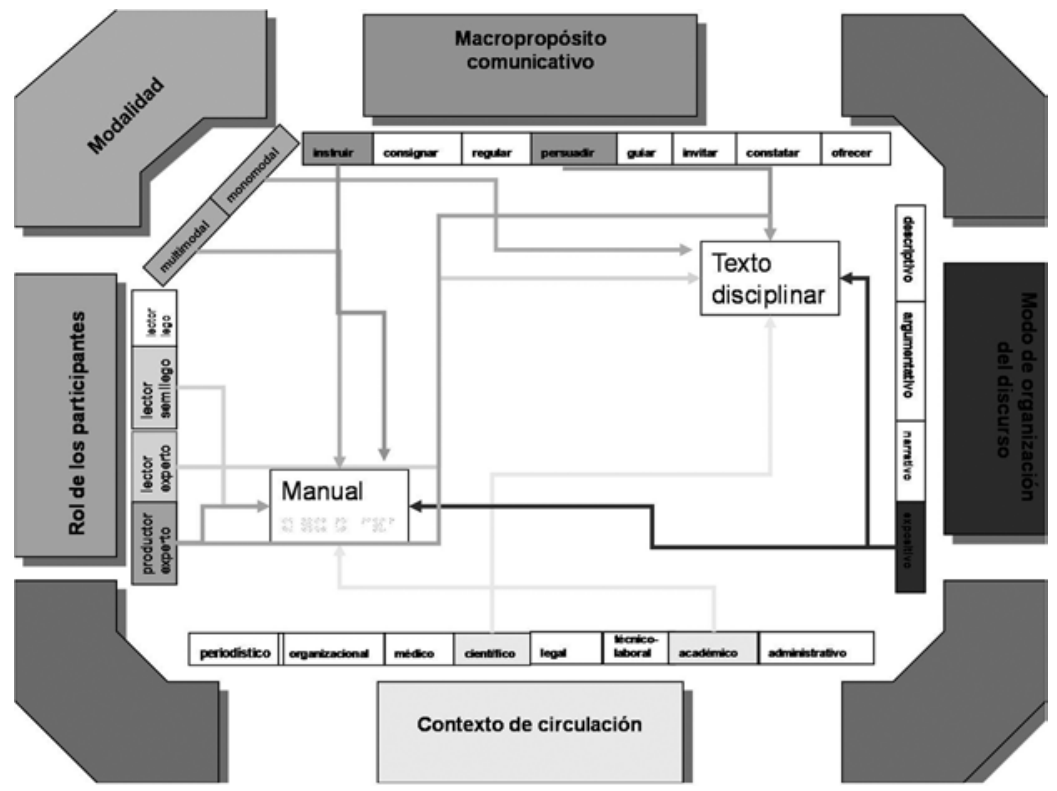


Como se observa a partir de esta figura, es posible identificar y distinguir el género Manual del género Texto Disciplinar a partir de la co-ocurrencia de las variables identificadas en cada uno de los criterios. Así, para el Manual, las variables prototípicas que lo configuran son: Macropropósito: instruir; Modo de organización del discurso: descriptivo; Contexto ideal de circulación: pedagógico; Relación entre los participantes: escritor experto y lector experto o semilego; Modalidad: multimodal. En tanto, para el Texto Disciplinar, las variables prototípicas que lo caracterizan son: Macropropósito: persuadir; Modo de organización del discurso: argumentativo; Contexto ideal de circulación: científico; Relación entre los participantes: escritor experto a lector experto; Modalidad: monomodal.

Los géneros Manual y Texto Disciplinar se diferencias en los cinco criterios, ya que tienen prototípicamente macropropósitos distintos (instruir vs. persuadir), modos de organización discursiva diversa (descriptivo vs. argumentativo), circulan idealmente en contextos diferentes (pedagógico vs. científico), la relación ideal entre lector y escritor es distinta (lector experto o semilego vs. lector experto) y presentan -preferentementemodalidades diferentes (multimodal vs. monomodal). Como se aprecia en la comparación de estos dos géneros, los criterios y variables seleccionados permiten identificar claramente un género de otro y hacer emerger las diferencias fundamentales entre ellos.

\section{Resultados}

En este apartado, a través de la aplicación de la matriz de los criterios y las variables a los textos del corpus, llegamos a la identificación de veintinueve géneros. Estos géneros son analizados en detalle en Parodi (2008). En lo que sigue, ellos se definen siguiendo un patrón basado en los criterios empleados. Ejemplos de cada uno de estos géneros pueden ser revisados en:

http://www.linguistica.cl/prontus_linguistica/site/artic/20081118/ asocfile/20081118135410/anexo_capitulo_2.pdf

\subsection{Definiciones}

A continuación, se presentan, en orden alfabético, las definiciones para cada uno de los veintinueve géneros del corpus PUCV-2006.

1. Artículo de investigación científica: Género discursivo cuyo macropropósito comunicativo es persuadir respecto de un determinado punto de vista, asumido en una revisión teórica o respecto de los re- 
sultados obtenidos en un estudio empírico. Idealmente, su contexto de circulación es el ámbito científico y la relación entre los participantes es entre escritor experto y lector experto. Preferentemente, se hace uso de un modo de organización discursiva, predominantemente, argumentativo y con apoyo de recursos multimodales.

2. Base de Licitación: Género discursivo que tiene como macropropósito invitar. La invitación emana de un ente público o institucional y se dirige a organizaciones y/o empresas para que formulen propuestas de ejecución de un servicio determinado. En este sentido, la relación entre los participantes es entre escritor experto y lector experto y el contexto ideal de circulación es el ámbito laboral. Generalmente, se trata de un género monomodal cuyo modo de organización discursiva predominante es el descriptivo.

3. Catálogo Comercial: Género discursivo cuyo macropropósito es ofrecer productos y/o servicios. La relación entre los participantes es entre escritor experto y lector experto y el ámbito ideal de circulación de este género es el laboral. Generalmente, presenta recursos multimodales y predomina un modo de organización discursiva descriptivo.

4. Certificado: Género discursivo que tiene como macropropósito constatar un determinado hecho administrativo. Se produce normalmente a instancias de quien lo solicita, y por una persona con autoridad suficiente dentro de una institución o empresa para establecer que se ha cumplido con lo afirmado en el documento. La relación entre los participantes es entre escritor experto y lector lego y el ámbito de circulación ideal es el universal. El certificado presenta un modo de organización discursiva predominantemente descriptivo y se privilegia la monomodalidad.

5. Convocatoria: Género discursivo cuyo macropropósito es invitar públicamente a una o varias personas o instituciones a realizar una actividad determinada bajo criterios preestablecidos. Los participantes configuran una relación entre escritor experto y lector experto. El ámbito de circulación es generalmente laboral. El modo de organización discursiva que predomina en este género es descriptivo y su presentación privilegia el uso de recursos monomodales.

6. Conferencia: Género discursivo que tiene como macropropósito persuadir en el marco de una relación que puede configurarse entre escritor experto y lector experto o semilego en un ámbito científico. Preferentemente, se hace uso de un modo de organización discursiva argumentativo y de recursos multimodales.

7. Cotización: Género discursivo cuyo macropropósito es constatar el valor de un bien o servicio. Idealmente, circula en el ámbito laboral. La relación entre los participantes puede ser entre escritor experto y 
lector experto o semilego. Preferentemente, se hace uso de un modo de organización discursiva descriptivo y de recursos multimodales.

8. Declaración: Género discursivo cuyo macropropósito es consignar una decisión, intención o acuerdo acerca del estado, condición o naturaleza de algo. Normalmente, circula dentro de un ámbito universal y la relación entre los participantes es entre escritor experto y lector experto. Se utiliza la descripción como modo de organización discursiva predominante y es monomodal.

9. Diccionario: Género discursivo cuyo macropropósito es consignar la definición de conceptos o procedimientos de una disciplina o materia determinada. Su contexto de circulación ideal es el ámbito pedagógico y la relación entre los participantes puede ser entre escritor experto y lector experto o semilego. Preferentemente, se hace uso de un modo de organización discursiva que es descriptivo y de recursos multimodales.

10. Ficha Médica: Género discursivo cuyo macropropósito es consignar el estado de salud de un paciente y de los procedimientos empleados para su tratamiento. Es utilizado entre escritores expertos y lectores expertos dentro del ámbito laboral. Es monomodal y presenta un modo de organización discursiva predominantemente descriptivo.

11. Folleto: Género discursivo cuyo macropropósito es ofrecer productos, servicios y/o informaciones. Circula, preferentemente, en un ámbito universal y la relación entre los participantes es entre escritor experto y lector semilego o lego. El modo de organización discursiva predominante es descriptivo y se suele apoyar en recursos multimodales.

12. Guía Didáctica: Género discursivo cuyo macropropósito comunicativo es instruir acerca de una materia disciplinar específica y/o procedimientos. Su contexto de circulación ideal es el ámbito pedagógico y la relación entre los participantes es entre escritor experto y lector semilego o lego. Preferentemente, se hace uso de un modo de organización discursiva que es argumentativo y, en ocasiones, de recursos multimodales.

13. Informe: Género discursivo cuyo macropropósito es consignar situaciones, procedimientos y/o problemas. Idealmente, su contexto de circulación es el ámbito laboral y la relación entre los participantes es entre escritor experto y lector experto. Suele ser monomodal y presentar un modo de organización discursiva que es descriptivo.

14. Ley: Género discursivo cuyo macropropósito es regular la conducta de los individuos y la ejecución de procedimientos y procesos diversos. Circula, idealmente, en el ámbito universal y la relación entre los participantes es entre escritor experto y lector experto o semilego. 
Es monomodal y presenta el modo de organización discursiva predominantemente descriptivo.

15. Manual: Género discursivo cuyo macropropósito comunicativo es instruir acerca de conceptos y/o procedimientos en una temática especializada. Su contexto de circulación ideal es el ámbito pedagógico y la relación entre los participantes es entre escritor experto y lector semilego o lego. Preferentemente, se hace uso de un modo de organización discursiva descriptivo y de recursos multimodales.

16. Manual de Operaciones: Género discursivo cuyo macropropósito es regular conductas y/o procedimientos. Idealmente, circula en el ámbito laboral y entre escritor experto y lector experto. Normalmente, se hace uso de recursos multimodales y el modo predominante de organización discursiva es el descriptivo.

17. Memorando: Género discursivo cuyo macropropósito comunicativo es constatar la entrega de información solicitada. Idealmente, circula en el ámbito laboral y la relación entre los sujetos participantes es entre escritor experto y lector experto. El modo de organización discursiva predominante es descriptivo y se hace uso de recursos monomodales.

18. Memoria de Cálculo: Género discursivo cuyo macropropósito comunicativo es consignar procedimientos utilizados en alguna de las fases de una construcción. Circula en un ámbito laboral y la relación entre los participantes es entre escritor experto y lector experto. El modo de organización discursiva predominante es descriptivo y se hace uso de recursos multimodales.

19. Norma: Género discursivo cuyo macropropósito comunicativo es regular conductas y/o procedimientos. Circula en el ámbito universal y la relación entre los participantes es entre escritor experto y lector experto o semilego. Suele ser monomodal y presentar un modo de organización discursiva que es, predominantemente, descriptivo.

20. Noticia: Género discursivo cuyo macropropósito es constatar hechos de diversa naturaleza. Idealmente, circula en el ámbito universal y la relación entre los participantes es entre escritor experto y lector experto, semilego o lego. El modo de organización discursiva predominante es narrativo. Se suele hacer uso de recursos multimodales.

21. Orden Médica: Género discursivo cuyo macropropósito comunicativo es guiar la ejecución de algún procedimiento médico. Circula en el ámbito laboral y la relación entre los participantes es entre escritor experto y lector experto. Es monomodal y su modo de organización discursiva es, predominantemente, descriptivo.

22. Pauta de Observación: Género discursivo cuyo macropropósito comunicativo es regular la observación de alguna cosa o evento. 
Circula entre escritor experto y lector experto e, idealmente, en el ámbito laboral. Es, generalmente, monomodal y su modo de organización discursivo es descriptivo.

23. Plan de Desarrollo: Género discursivo cuyo macropropósito comunicativo es guiar acciones para encauzar el logro de uno o más objetivos. Circula entre escritor experto y lector experto y en el ámbito laboral. Se hace uso de recursos multi-modales y su modo de organización discursiva predominante es descriptivo.

24. Plano: Género discursivo cuyo macropropósito es guiar la organización y distribución de una obra arquitectónica, una población o una máquina. La relación entre los participantes es entre escritor experto y lector experto. Idealmente, circula en el ámbito laboral y se caracteriza por contar con una predominancia de recursos multimodales, así como con un modo de organización discursiva que es descriptivo.

25. Proyecto de Investigación: Género discursivo cuyo macropropósito comunicativo es ofrecer una propuesta de investigación científica. Idealmente, circula en el ámbito científico y entre escritor experto y lector experto. Se utiliza recursos monomodales y se caracteriza por presentar un modo de organización discursiva que es argumentativo.

26. Registro: Género discursivo cuyo macropropósito es consignar el estado de un procedimiento o producto. Circula en el ámbito laboral y la relación entre los participantes es entre escritor experto y lector experto. El modo de organización discursiva característico de este género es el descriptivo. Se suele utilizar recursos monomodales.

27. Tesis: Género discursivo que tiene como macropropósito persuadir acerca de un planteamiento teórico o ideológico. Idealmente, circula en el ámbito científico y la relación entre los participantes es entre escritor experto y lector experto. El modo de organización discursiva predominante es argumentativo. Se suele emplear recursos multimodales.

28. Test: Género discursivo cuyo macro-propósito comunicativo es consignar características psicológicas de un sujeto. Circula en el ámbito laboral y la relación entre los participantes es entre escritor experto y lector lego. Puede ser multimodal y su modo de organización discursiva preferente es el descriptivo.

29. Texto Disciplinar: Género discursivo cuyo macropropósito comunicativo es persuadir respecto del tratamiento de uno o varios temas de una disciplina particular. Idealmente, su contexto de circulación es el ámbito científico y la relación de los participantes es entre escritor experto y lector experto. Preferentemente, se hace uso de un modo de organización discursiva que es argumentativo. También se emplea recursos multimodales. 


\subsection{Análisis de los géneros identificados según el marco de análisis}

En lo que sigue, se presenta un análisis a partir de los veintinueve géneros identificados en el corpus, tomando como punto de partida cada una de las variables operacionalizadas desde los criterios de base. En primer lugar, abordamos el Macropropósito Comunicativo. En la Figura 6 se presentan los géneros agrupados en torno a los ocho macropropósitos.

Figura 6. Clasificación de los géneros académicos y profesionales según macropropósitos comunicativos

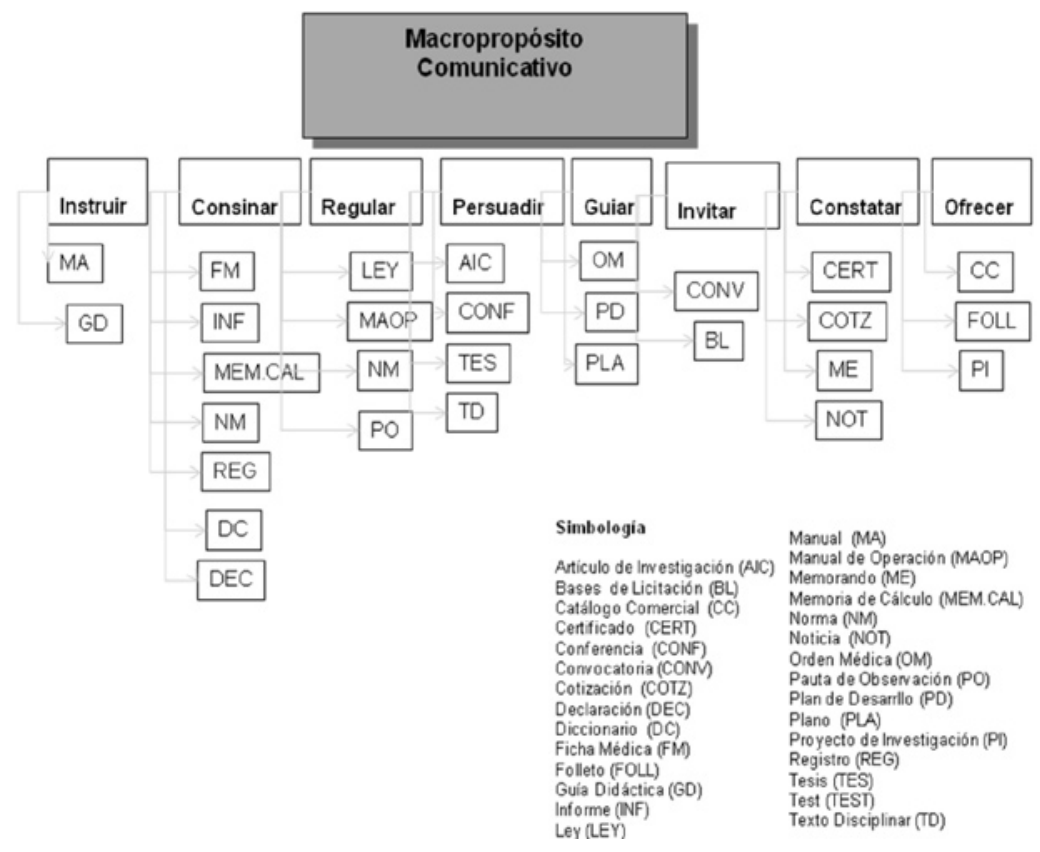

Como se puede observar en la Figura 6, de los veintinueve géneros identificados, siete de ellos revelan predominancia del macropropósito consignar. Esta ocurrencia alcanza el $24,13 \%$ del total, hecho que lo transforma en el macropropósito más frecuente entre los géneros del corpus. Al mismo tiempo, cuatro géneros (Ley, Manual de Operación, Norma, Pauta de Observación) se corresponden con el propósito regular $(13,8 \%)$, otros cuatro géneros (Artículo de Investigación Científica, Conferencia, Tesis y Texto Disciplinar) comparten el macropropósito persuadir y otros cuatro (Certificado, Cotización, Memorando, Noticia) coinciden en el macropropósito constatar. Por su parte, los propósitos guiar (10,3\%) y ofrecer $(10,3 \%)$ reúnen cada uno a tres géneros diferentes. Por último, los 
macropropósitos instruir (6,9\%) e invitar (6,9\%) aglutinan a dos géneros cada uno. Según se aprecia y a partir de estos datos, es posible establecer que, aun cuando el corpus es de naturaleza académica y profesional, el macropropósito predominante de los géneros aparece más orientado al ámbito profesional que al académico.

A continuación, revisamos la distribución de géneros respecto del criterio Modo de Organización del Discurso. Este modo se operacionaliza en tres variables.

El siguiente criterio en análisis es el Contexto Ideal de Circulación, cuyos datos se grafican en la Figura 8.

Figura 7. Clasificación de los géneros profesionales y académicos según el modo de organización del discurso

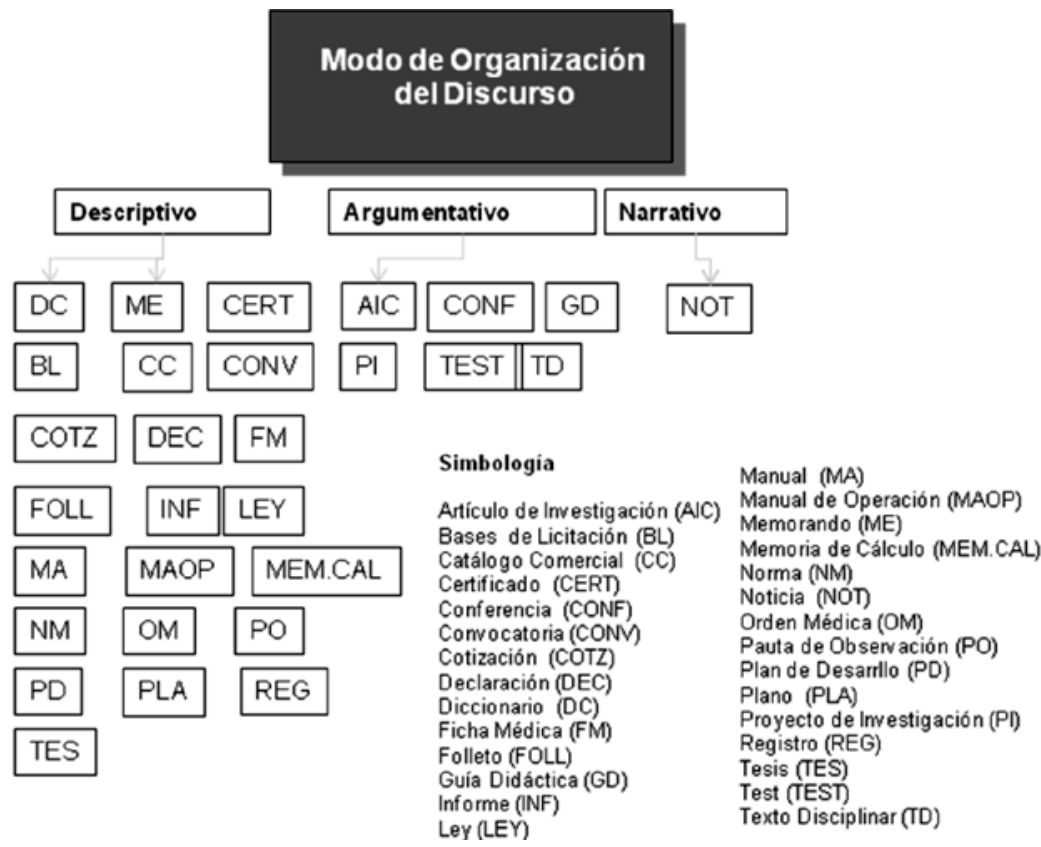

En la Figura 7 observamos que la gran mayoría de los géneros presentan un modo predominantemente Descriptivo (Diccionario, Memorando, Certificado, Base de Licitación, Catálogo Comercial, Convocatoria, Cotización, Declaración, Ficha Médica, Folleto, Informe, Ley, Manual, Manual de Operaciones, Memoria de Cálculo, Norma, Orden Médica, Pauta de Observación, Plan de Desarrollo, Plano, Registro y Tesis). Este modo aglutina al $75,9 \%$ de los géneros identificados en el corpus. Por otra parte, seis géneros presentan predominancia del modo argumen- 
tativo (Artículo de Investigación Científica, Conferencia, Guía Didáctica, Proyecto de Investigación, Tesis y Texto Disciplinar), lo que corresponde al 13,8\%. Por último, solo uno (Noticia) presenta predominancia del modo narrativo, equivalente al 3,4\%. Dada la naturaleza académica y profesional del corpus en estudio, estos datos adquieren especial relevancia al comprobar que su rasgo predominante, como modo de organización del discurso, muestra una tendencia hacia la descripción por sobre los otros dos modos.

Figura 8. Clasificación de los géneros profesionales y académicos según el contexto ideal de circulación

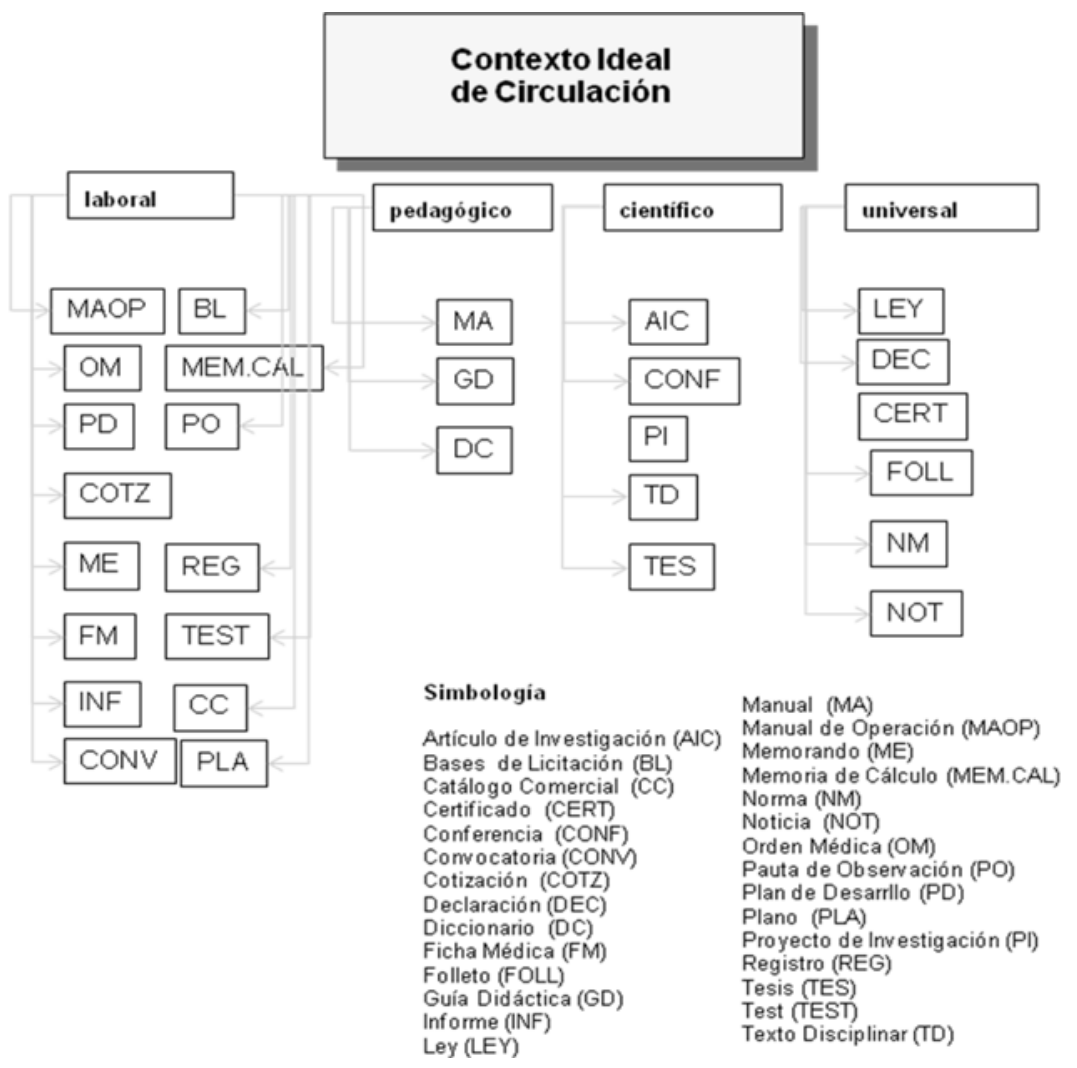

En cuanto al Contexto Ideal de Circulación de estos veintinueve géneros, podemos establecer que el contexto laboral (con un $48,3 \%$ de los géneros) es el que reúne a la mayoría de los géneros del corpus: Memorando, Base de Licitación, Catalogo Comercial, Convocatoria, Cotización, Ficha Médica, Informe, Manual de Operaciones, Memoria de Cálculo, Orden Médica, Pauta de Observación, Plan de Desarrollo, Registro y Test. En segundo lugar, se destaca el contexto de tipo universal, el cual da cuenta del $24,1 \%$ de los géneros el corpus (Ley, Diccionario, Certificado, 
Folleto, Norma, Noticia y Plano). En tercer lugar, se ubica el contexto denominado como científico, el cual reúne al 17,2\% de los géneros (Artículo de Investigación Científica, Conferencia, Proyecto de Investigación, Texto Disciplinar y Tesis). Con un porcentaje mucho menor de géneros $(10,3 \%)$, se presenta el contexto pedagógico, el cual aglutina al Manual, la Guía Didáctica y al Diccionario. El agrupamiento de estos géneros, de acuerdo a este criterio, revela que, aunque muchos de estos géneros pueden circular en el contexto académico, idealmente son producidos desde contextos de tipo profesional.

A continuación, en la Figura 9, se observa que el 100\% de los géneros del corpus son creados por escritores expertos. Lo que establece la diferencia en la relación entre los participantes es el tipo de lector al cual el género va dirigido.

Figura 9. Clasificación de los géneros profesionales y académicos según la relación entre los participantes

Relación entre los

participantes

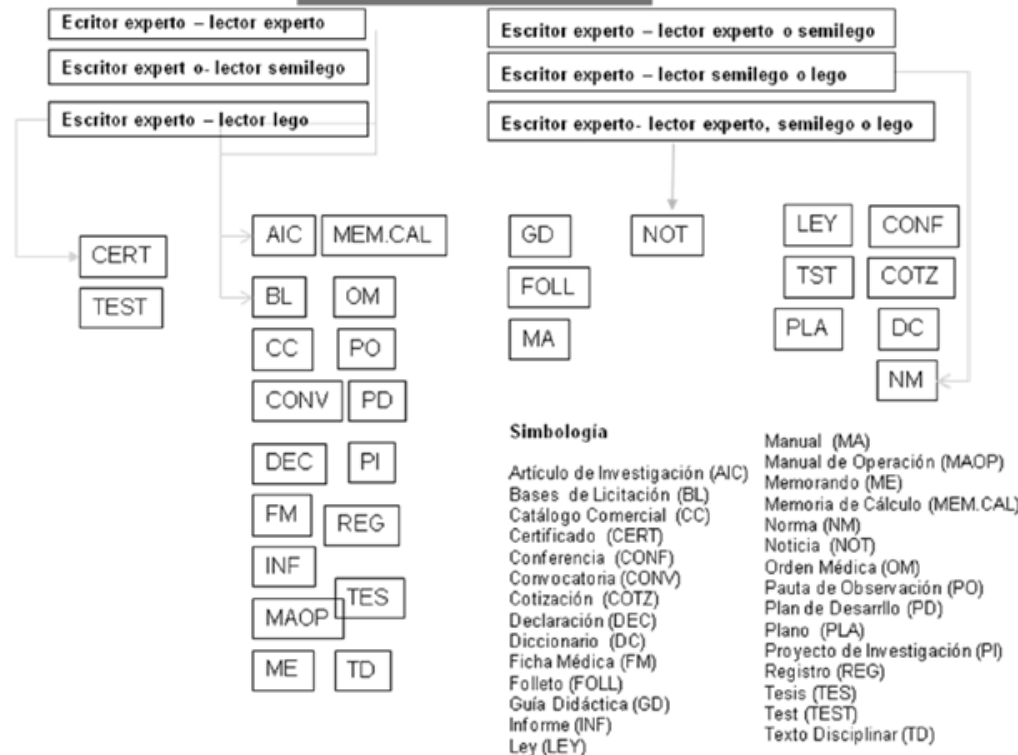

Como se puede observar en la Figura 9, los géneros Certificado y Test $(6,9 \%)$ son creados exclusivamente para lectores legos. Por otra parte, la Guía Didáctica, el Folleto y el Manual son producidos para lectores semilegos o legos, lo que corresponde al 10,3\%. Así también, la Conferencia, la Cotización, el Diccionario, la Norma, la Ley y el Plano son producidos 
para ser leídos por lectores expertos o semilegos (24,1\%). Por último, se detecta un grupo de diecisiete géneros, correspondientes al 58,6\%, los cuales han sido producidos para ser leídos por expertos (Artículo de Investigación Científica, Base de Licitación, Catálogo Comercial, Convocatoria, Declaración, Ficha Médica, Informe, Manual de Operaciones, Memorando, Memoria de Cálculo, Pauta de Observación, Plan de Desarrollo, Proyecto de Investigación, Registro, Test y Texto Disciplinar). Esto es, se trata de géneros que exigen un alto grado de conocimiento previo para poder ser comprendidos y utilizados. Solo la Noticia es creada para lectores diversos como los expertos, semilegos o legos.

El siguiente criterio en análisis corresponde a la Modalidad. La distribución de los géneros de acuerdo a este criterio se presenta en la Figura 10.

Figura 10. Clasificación de los géneros profesionales y académicos según la modalidad

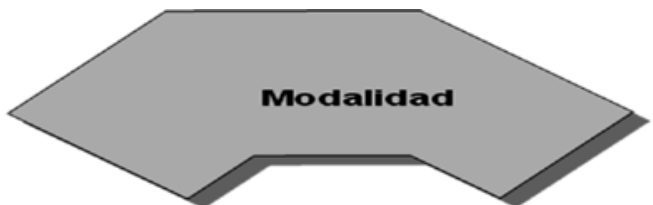

multimodal

monomodal

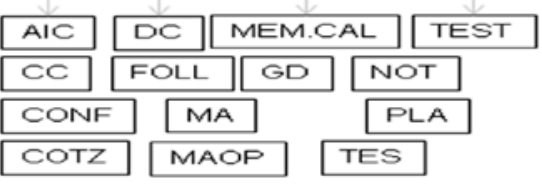

Simbología

Artículo de Investigación (AVC) Bases de Licitación (BL)

Catálogo Comercial

Conferencia (CONF)

Comvocato ria (CONM

Cotización (COTZ)

Declaración (DEC)

Diccionario (De)

Folleto (FOL

Guía Didactica (GD)

forme (INF)

LeY (LEY)

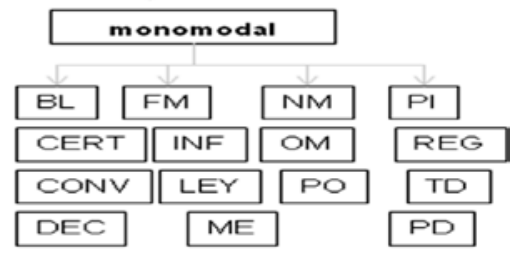

Manual (MA)

Manual de Operación (MAOP)

Memoria de Cálculo (MEM.CAL)

Norma (NM

Noticia (NOT

Orden Médica (OM)

Pauta de Observación (PO)

Plan de Desarrllo (PD)

Plano (PLA)

Proyecto de Imvestig ación (PI)

Registro (REG)

Tesis (TES)

Texto Disciplinar (TD)

Como se observa en la Figura 10, en el $51,7 \%$ de los géneros del corpus predomina la monomodalidad. Por otra parte, en el $48,3 \%$ predomina la complementación del modo verbal escrito con otros modos semióticos, particularmente con imágenes, gráficos y fórmulas científicas. Este hallazgo revela un equilibrio en la distribución de los géneros respecto de este criterio. 
El Corpus PUCV-2006 del Español: identificación y definición de los géneros discursivos académicos y profesionales / Giovanni Parodi, Romualdo Ibáñez y René Venegas

\section{Conclusiones}

Tal como se ha demostrado a partir de este estudio empírico, el empleo de múltiples variables de diversa índole constituye en conjunto un soporte teórico-empírico robusto en comparación a aproximaciones basadas en uno o pocos criterios. Junto a ello, el supuesto inicial de que las categorías son difusas y que los límites entre uno y otro género se pueden presentar de modo poroso ha probado ser una herramienta útil, a partir de la cual se detectan géneros muy cercanos que comparten uno o varios rasgos. No obstante ello, también se identifican géneros muy disímiles que podrían ubicarse en polos extremos. Al mismo tiempo, la idea de predominancia de un rasgo por sobre otros, dentro de un mismo criterio, se implementó como un modo de incluir el supuesto de que los objetos en estudio están constituidos por haces de rasgos complejos co-ocurrentes y no por características únicas, simples y homogéneas. En este sentido, la búsqueda de una variable como predominante por sobre otras ha sido un principio rector de nuestro análisis. Este mismo enfoque se detecta a lo largo de Parodi (2008), pues la naturaleza compleja y multidimensional de los géneros exige una aproximación ad hoc de similar característica.

Los cinco criterios identificados y seleccionados en esta investigación, así como las veintiséis variables más concretas y específicas en que estos se operacionalizan han permitido distinguir casi todos lo géneros identificados en el corpus. En los casos de Artículo e Investigación y Texto Disciplinar no se ha logrado identificar una diferencia sustancial a partir de los criterios. Esto, sin duda, implica que se deben afinar aún más los criterios de modo de poder producir definiciones distintivas para cada género. En todo caso, esta matriz compleja de multidimensiones ha posibilitado la elaboración de definiciones operacionales, la ejemplificación y la clasificación de la gran mayoría de los géneros identificados. Este se constituye en el principal aporte de este estudio.

La construcción de una propuesta multidimensional desde una concepción compleja y dinámica de los géneros del discurso escrito ha sido también uno de los propósitos subyacentes a esta investigación. Para ello, hemos puesto en práctica una metodología complementaria en que se conjugan métodos deductivos e inductivos. No cabe duda que su aplicación a un corpus del tamaño y extensión de los textos constitutivos del Corpus Académico y Profesional del Español PUCV-2006 no ha resultado una tarea fácil y ha significado un desafío para el equipo de investigadores.

Estamos seguros que tanto la construcción de una taxonomía compleja así como su operacionalización en géneros específicos se constituye en 
un camino inicial que debe continuar hacia una progresiva contrastación empírica. Diversas aproximaciones y procedimientos deberán validar esta propuesta y mostrar sus fortalezas y debilidades.

\section{Bibliografía}

Adam, J-M. (1992). Les textes: Types et prototypes. Paris: NathanUniversité.

Askehave, I. \& Swales, J. (2001). “Genre identification and communicative purpose: A problem and a possible solution". Applied Linguistics, 22(2), 95-212.

Bassols, M., \& Torrens, A. (1997). Modelos textuales, teoría y práctica. Barcelona: Eumo Editorial.

Bhatia, V. (1993).

Analysing genre:Language use in professionalsettings. London: Longman.

(1997).

Introduction: "Genre analysis and world Englishes". World Englishes, 16, 313-319.

(2004).

Worlds of written discourse. A genre based view. Sydney: Continuun.

Biber, D., Connor, U., \& Upton, T. (2007). Discourse on the move. Using corpus analysis to describe discourse structure. Amsterdam: Benjamins.

Charaudeau, P. (1992). Grammaire du sens et de l'expression. Paris: Hachette.

Ciapuscio, G. (2003). Textos especializados y terminología. Barcelona: IULA.

De Beaugrande, R. \& Dressler, W. (1981). Introducción a la lingüística del texto. Barcelona: Ariel.

Dudley-Evans, T. (1994). "Genre analysis: An approach for text analysis for ESP". En M. Coulthard (Ed.), Advances in written text analysis (pp. 219-228). London: Routledge.

Eco, U. (2000).

Tratado de semiótica general. Barcelona: Lumen.

Halliday, M. (2004).

"The ontogenesis of dialogue". En J. Webster (Ed.), The language of early childhood (pp. 144-152). London: Continuum.

\& Hasan, R. (1976). Cohesión in English. London: Longman. 
El Corpus PUCV-2006 del Español: identificación y definición de los géneros discursivos académicos y profesionales / Giovanni Parodi, Romualdo Ibáñez y René Venegas

Hamon, P. (1991). Introducción al análisis de lo descriptivo. Buenos Aires: Edicial.

Kress, G. \& van Leeuwen, T. (2001). Multimodal discourse. London: Arnold.

Lakoff, G. (1972). "A study in meaning criteria and the logic of fuzzy concepts". Linguistics Society, 8, 183-288.

Lo Cascio, V. (1998). Gramática de la argumentación. Madrid: Alianza.

Martin, J. \& Matthiessen, C. (1991). “Systemic typology and topology”. En F. Christie (Ed.) Literacy in social processes: Papers from the first Australian systemic linguistics Conference, January 1990 (pp. 345-383). Darwin: Centre for Studies of Language in Education.

Martin, J. (1993). Writing science. Literacy and discursive power. Pittsburgh: University of Pittsburgh.

(1996).

"Types of structure: Deconstructing notions of constituency in clause and text". En E. Hovy \&D. Scott (Eds.), Burning issues in discourse: A multidisciplinary perspective (pp. 198-234). Heidelberg: Springer.

"A universe of meaning - how many practices?" En A. Johns (Ed.), Genre in the classroom: Multiple perspectives (pp. 269-278). New York: Erlbaum.

Parodi, G. (Ed.) (2008). Géneros Académicos y Géneros Profesionales: Accesos Discursivos para Sabery Hacer. Valparaíso: Ediciones Universitarias de Valparaíso.

(2009a). "Géneros discursivos y lengua escrita: Propuesta de una concepción integral desde una perspectiva sociocognitiva". Revista Letras (en prensa).

(2009b).

“Corpus PUCV-2006 del Español: el género manual y su organización retórica". Revista Signos (en prensa).

y Gramajo, A. (2003). "Los tipos textuales del corpus PUCV-2003: Una aproximación multiniveles". Revista Signos, 36, 207223.

Pierce, C. S. (1965).

"Collected papers of Charles Sanders Pierce". En Ch. Hartshorne \& P. Weiss (Eds.), Collected papers of Chales Sanders Pierce. Cambridge, MA: Harvard University Press.

Propp, V. (1928).

Morfología del cuento. Madrid: Fundamentos.

Rosch, E. (1975).

"Cognitive representations of semantic categories". Journal of Experimental Psychology: General, 104, 192-233. 
Swales, J. (1990). (2001). (2004).

Tognini-Bonelli, E. (2001)

Toulmin, S. (1958).

van Dijk, T. (1983).

Wittgenstein, L. (1958).
Genre análisis. English in academic and research settings. Cambridge: Cambridge University Press.

"EAP-related linguistic research: An intellectual history". En J. Flowerdew \& M. Peacock (Eds.), Research perspectives on English for academic purposes (pp. 42-54). Cambridge: Cambridge University Press.

Research Genres: Exploration and applications. Cambridge: Cambridge University Press.

Corpus linguistics at work. Amsterdam: Benjamins.

The uses of argument. Londres: Cambridge

Ciencia del texto: Un enfoque interdisciplinario. Barcelona: Serie

Philosophical investigations. Oxford: Blackwell. 